\title{
Integrating Safety and Health Indexes in Computer-Aided Molecular Design Under Property Prediction Uncertainty
}

(Date Received: 25.04.2017/Date Accepted: 01.08.2017)

\author{
Joon Yoon Tena, Lik Yin Ng', Mimi H. Hassimc, Denny Ng K.S. ${ }^{\text {a }}$ and Nishanth G. Chemmangattuvalappila* \\ ${ }^{a}$ Department of Chemical and Environmental Engineering/Centre of Excellence for Green Technologies, \\ The University of Nottingham Malaysia Campus, Broga Road, 43500 Selangor D.E., Malaysia.
}

${ }^{b}$ Universiti Tunku Abdul Rahman, Jalan Sungai Long, Bandar Sungai Long, Cheras 43000, Kajang, Selangor D.E., Malaysia.

'Department of Chemical Engineering/Centre of Hydrogen Energy, Faculty of Chemical Engineering, Universiti Teknologi Malaysia, 81310 UTM Johor Bahru, Johor, Malaysia.

*E-mail: nishanth.c@nottingham.edu.my

\section{ABSTRACT}

Computer-Aided Molecular Design (CAMD) is a powerful tool for designing promising molecules with the targeted properties. Besides properties, the safety and health aspects must also be considered during design stage to ensure the synthesized molecules do not cause much harm. The molecules are assessed by several safety and health parameters, which are measured using physicochemical properties that can be estimated via property prediction methods. Each parameter/sub-index is allocated with a penalty score based on the property to represent the hazard level of molecules. However, uncertainty in the prediction models can adversely affect the accuracy of scores. The main highlight of this paper is to manage the effect of uncertainty on the safety and health sub-indexes, by improving the scores at the uncertain region for enhanced measurement of molecular hazards. A case study on solvent design for carotenoids extraction from Palm Pressed Fiber (PPF) has been considered with the proposed methodology.

Keywords: Carotenoids Extraction, Computer-Aided Molecular Design, Property Prediction Model, Safety and Health Index, Uncertainty.

\subsection{INTRODUCTION}

Many industrial disasters in the past were caused by the mishandling of hazardous substances, combustible dusts and reactive chemicals. ${ }^{1}$ The occurrences of such accidents have emphasized the importance of process safety as contributing factor in process design and development. The increase in complexity of processing plants due to continuing technological and social development has also resulted in new hazards and increased risk in chemical processing plants. ${ }^{2}$ As a result, hazard identification and analysis methods are introduced to manage hazards in the process. These techniques may be able to reduce the overall safety impacts of the plant, but it does not completely eliminate hazards present in the plant. Since many accidents are linked to the use of harmful chemicals, one way to address this is to replace the highly hazardous chemicals with less harmful ones. The substitution of dangerous chemicals can be accomplished by utilizing chemical product design techniques. The traditional product design technique involves trial-and-error laboratory synthesis and test methodology to synthesize a set of promising molecular candidates that attain the targeted results. However, this technique is unable to excel in the present global business environment as the need of experimental works is timeconsuming and costly. ${ }^{3}$ An alternate way is the top-down reverse engineering approach, which couples with computer-aided molecular design (CAMD) technique to identify the optimal molecular structures. ${ }^{4}$ CAMD aims to determine a molecule that meets the specified target properties from a given set of molecule building blocks. ${ }^{5}$ CAMD tools utilize optimization methods to generate molecules and applied property prediction models to evaluate the molecular performance based on the set of priori target property values. ${ }^{6}$ In the past few decades, the aspects of environment, safety and health have received much increased attention in many CAMD problems. Duvedi and Achenie ${ }^{7}$ applied CAMD technique to design environmentally-friendly refrigerants. As for safety and health, Karunanithi et al., ${ }^{8}$ included flammability and toxicity as design factors to synthesize solvents for solution crystallization.

Recently, Ten et al., ${ }^{9}$ considered the concept of inherent safety and occupational health as design objectives to evaluate the safety and health performance of the generated molecules. The aim is to ensure that the synthesized molecules have reduced hazards and do not cause much safety and health risks. The concept of Inherent Safety Design (ISD) is to eliminate or minimize hazards present in process plant by substituting hazardous substances with less dangerous materials. Numerous inherent safety indexes have been established to identify and quantify the hazard level in a process route. The pioneer of all inherent safety indexes was the Prototype Index for Inherent Safety (PIIS) developed by Edwards and Lawrence, ${ }^{10}$ which quantifies and ranks the inherent safety of several process routes during conceptual design stage. The Inherent Safety Index (ISI) by Heikkilä ${ }^{11}$ considered a wider scope of safety parameters that are readily available during preliminary design stage. As for occupational health, International Labor Organization (ILO) has predicted that over two million people around the world 
die yearly due to work-related diseases. Therefore, inherent occupational health has been introduced to minimize the health hazards posed by chemical processes to the workers. The Process Route Healthiness Index (PRHI) by Hassim and Edwards ${ }^{12}$ was developed to assess possible occupational health hazards arisen from process routes in early design phase. Meanwhile, the Inherent Occupation Health Index (IOHI) by Hassim and Hurme $^{13}$ evaluates the possible health risks of different process routes during research and development stage. Similarly to inherent safety indexes, both PRHI and IOHI used health based parameters to conduct the occupational health assessment of a process route.

In the inherent indexes, the chemical-related safety and health parameters are applied to measure the molecular performance. Each parameter/sub-index is assessed using one or few molecular properties, and subjective scaling is used where the properties are divided into a few ranges. Each range is then allocated with a score depending on the degree of potential hazards. Since all properties are estimated through property prediction methods, the accuracy of the estimated property values may not always be guaranteed. Generally, there are 5-10\% (or higher) of discrepancies between the actual experimental values and property predictions. ${ }^{14}$ Since the properties affect the sub-index scores, thus the allocation of scores is dependent on the accuracy of the predicted values. The deviation of predicted value from its actual experimental value may cause the assignment of inaccurate score to the molecule. As a result, the main objective of this paper is to manage uncertainty resulted from property prediction in the safety and health sub-indexes. The goal is to improve the scorings for better representation of molecular hazard level.

\subsection{METHODOLOGY}

\subsection{Problem Formulation}

The needs of a chemical product are first specified by defining the product specifications to determine the functionality and physical behavior of a product. These product specifications can be translated in terms of target properties, which are represented by the physicochemical properties of the molecules. Target properties are usually represented in terms of property range, in which the property value must fall within the predefined range for the molecule to function as intended. The target properties are then categorized as objective functions to be optimized or property constraints to be fulfilled. The possible molecular groups acting as the potential building blocks will be selected. Structural constraints are also introduced to eliminate combination of infeasible solution.

\subsection{Selection of Inherent Safety and Health Sub- Indexes}

For the selection of safety and health sub-indexes, the properties involved in the assessment of molecules must be able to be estimated through property prediction models. The safety and health sub-indexes chosen are shown in Figure 1. The properties used for the measurement of the sub-indexes are also listed in the figure. The total penalty score of a molecule (ISHI) is the summation of all seven sub-index scores assigned to it. A molecule with lower total penalty score is desired as it indicates a molecule with inherently safer and healthier properties.

\subsection{Property Prediction Models and Uncertainty Management}

All target properties in Section 2.1 and properties assessed in Figure 1 have to be calculated through the property prediction methods. One conventionally used approach is the group contribution method (GCM), which is able to estimate the physicochemical properties of a molecule based on its molecular structure. ${ }^{15}$ The general equation for the applied GCM is shown in Equation (1). $f(p)$ denotes the simple function of property $p$, while $C_{i}$ represents the contribution of molecular group of type- $i$ with $N_{i}$ occurrence. Flash point $\left(F_{p}\right)$, boiling point $\left(T_{b}\right)$ and melting point $\left(T_{m}\right)$ are estimated using models developed by Hukkerikar et al., ${ }^{16}$ Meanwhile, permissible exposure limit

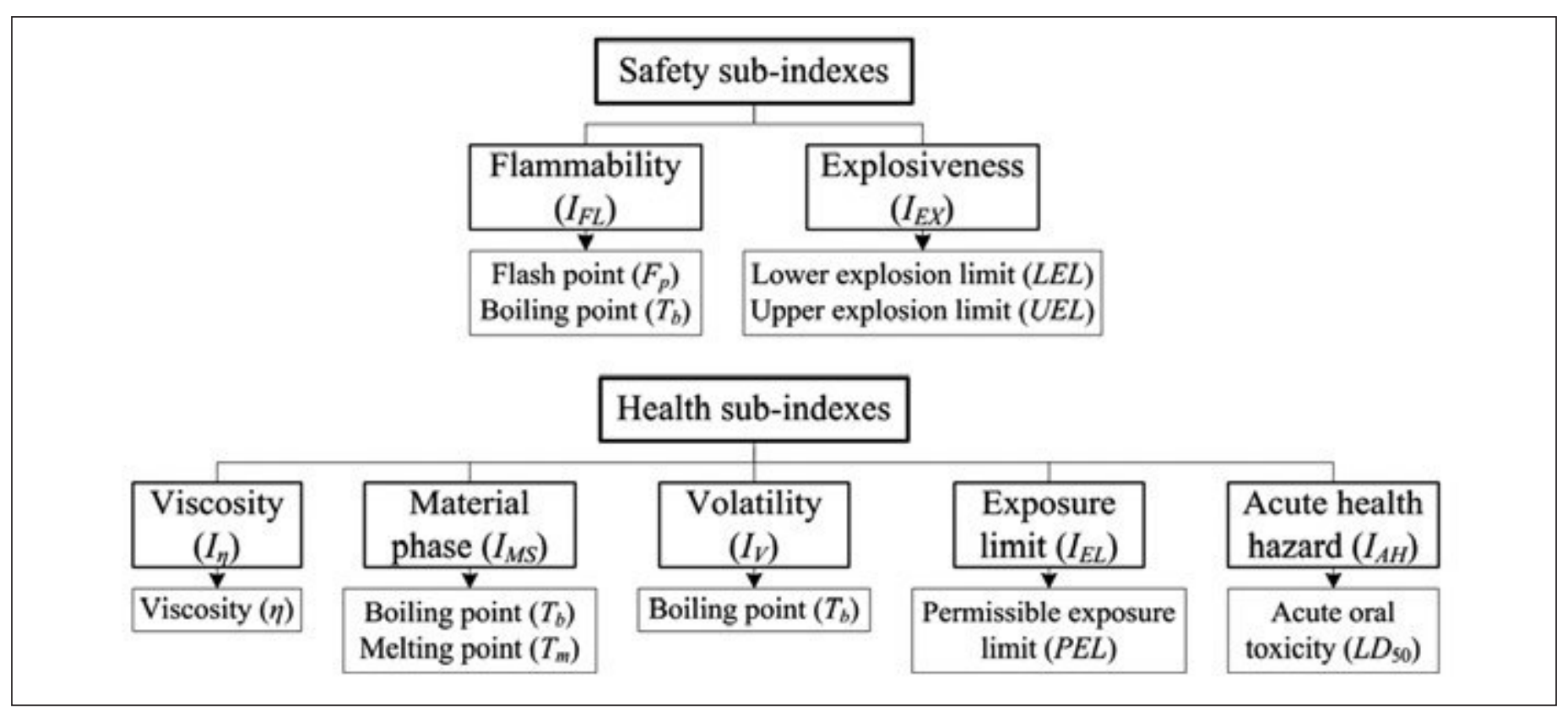

Figure 1: The selected safety and health sub-indexes and the properties used for assessment 


\section{INTEGRATING SAFETY AND HEALTH INDEXES IN COMPUTER-AIDED MOLECULAR DESIGN UNDER PROPERTY PREDICTION UNCERTAINTY}

(PEL) and $L D_{50}$ for acute oral toxicity can be estimated using models presented by Hukkerikar et al., ${ }^{17}$ Conte et al., ${ }^{18}$ have established a model to calculate viscosity $(\eta)$. Both upper and lower exposure limits ( $U E L$ and $L E L$ ) can be estimated using models proposed by Frutiger et al., ${ }^{19}$

$f(p)=\sum_{i} N_{i} C_{i}$

For all these GCM models, the estimated value may not always be close to the actual value. The deviation of the estimated value may result in an inaccurate sub-index value being allocated to the molecule. For instance, given that molecule $\mathrm{K}$ has an estimated $\eta$ value of $7.7 \mathrm{cP}$. As shown in Figure 2(a), its $I_{\eta}$ sub-index value would be two. However, the GCM for $\eta$ has a standard deviation of $3.44 \mathrm{cP} .{ }^{18}$ The exact $\eta$ value for molecule $\mathrm{K}$ can fall within the range of $7.7 \mathrm{cP} \pm 3.44$ $\mathrm{cP}$, which is represented by the grey region in Figure 2(a). Based on Figure 2(a), it is possible that its $I_{\eta}$ sub-index value can either be two or three, since $10 \mathrm{cP}$ is a boundary value where any $\eta$ values higher than it are allocated an $I_{\eta}$ value of three, whereas any $\eta$ values lower than it (but above $1 \mathrm{cP}$ ) are assigned an $I_{\eta}$ value of two. Thus from the diagram, when the property value moves across the boundary value, there is an abrupt change on the sub-index value. Therefore, the allocation of sub-index value to any property value that is near to the boundary value is highly uncertain. Hence, the management of property prediction uncertainty is carried out on this region. First, the standard deviation of GCM for $\eta$ has to be identified, which is $3.44 \mathrm{cP}$. This value is added to or subtracted from the boundary value, 10
$\mathrm{cP}$, to create the uncertain range $(6.56 \mathrm{cP}$ to $13.44 \mathrm{cP}$, the grey zone in Figure 2(b)). When $\eta$ is $6.56 \mathrm{cP}$, the initial $I_{\eta}$ value is two; when $\eta$ is $13.44 \mathrm{cP}$, the initial $I_{\eta}$ value would be three. In the uncertain range, the $I_{\eta}$ value linearly transits from two (at 6.56 $\mathrm{cP}$ ) to three (at $13.44 \mathrm{cP}$ ). This transition is represented by the slope drawn on the uncertain range.

Meanwhile, Figure 3(a) illustrates the scorings of $I_{A H}$ subindex. The standard deviation of GCM for $\log L D_{50}$ is $0.43 .{ }^{17}$ The management of uncertainty is done on the two boundary values (2.7 and 3.3) as shown in Figure 3(a), and the uncertain range for both boundary values are determined. However, there exists an overlapping of uncertain range for both boundary values (darker grey region in Figure 3(a)). Two linear slopes are drawn on the uncertain range for both boundary values. As shown in Figure 3(b), the overlapping region contains two different transition slopes contributed by each boundary value. However, any property value at any region can only receive a single subindex value to indicate its hazard level. Hence, composite curve is applied on this overlapping region, which is shown in Figure 3(c). The management of uncertainty is repeated for all boundary values of all sub-indexes but $I_{F L}$ and $I_{E X}$ sub-indexes, as both subindexes are each measured by two properties. Each GCM model has its distinct statistical performance indicator values and to address different uncertainties originated from multiple GCM models, the CAMD model would become complex.

\subsection{Optimization Model}

In this paper, the CAMD problem considers multiple design

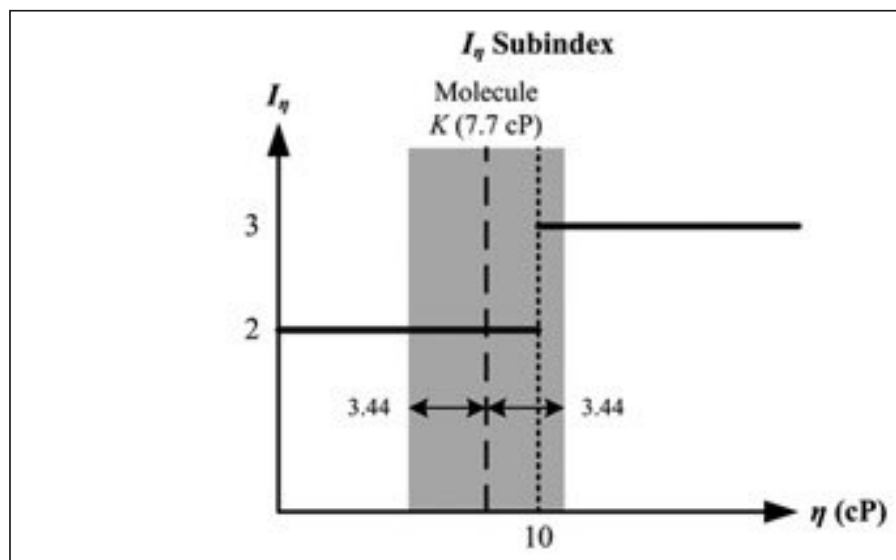

(a)

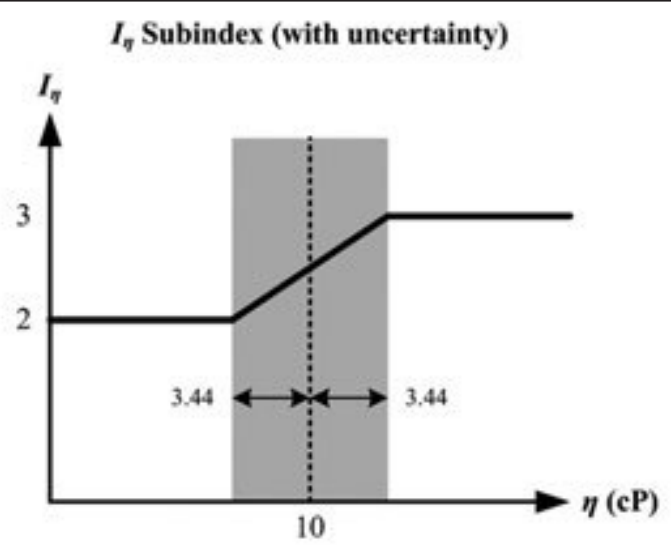

(b)

Figure 2: (a) Initial form of $I_{\eta}$ sub-index; (b) $I_{\eta}$ sub-index with the incorporation of uncertainty

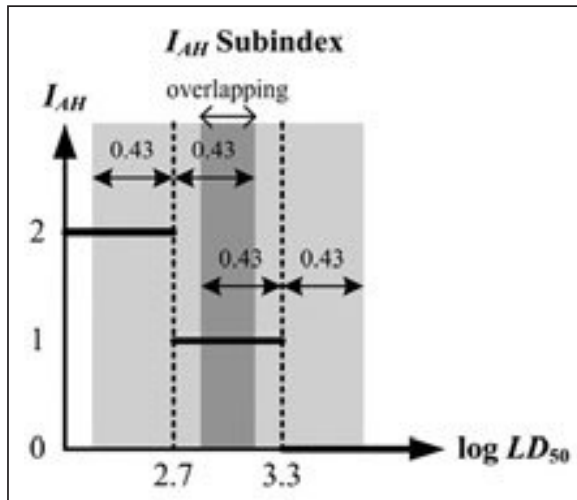

(a)

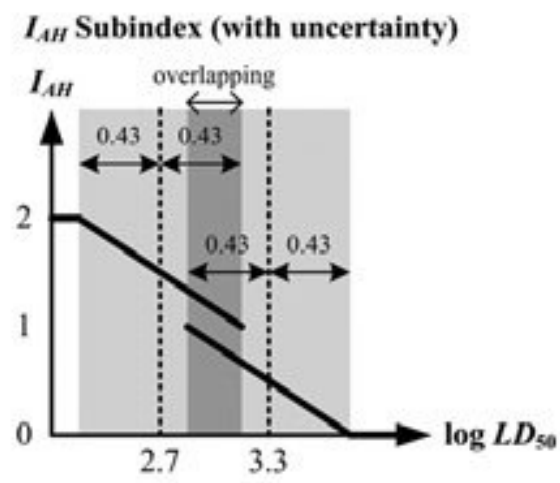

(b)

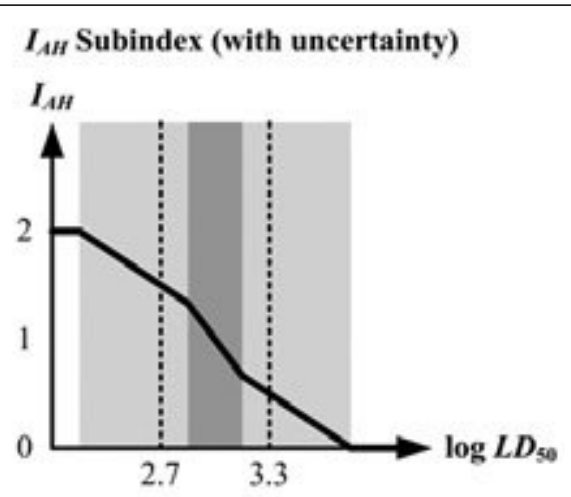

(c)

Figure 3: (a) Initial form of IAH sub-index; (b) IAH Sub-index with the incorporation of uncertainty; (c) IAH Sub-index with composite curve 


\section{JOON YOON TEN ${ }^{a}$, LIK YIN NG ${ }^{b}$, MIMI H. HASSIMc, DENNY NG K.S. ${ }^{a}$ AND NISHANTH G. CHEMMANGATTUVALAPPIL ${ }^{a *}$}

objectives, in which the product functionality and its safety and health attributes are optimized simultaneously. A decision making has to be made on the trade-off between different objectives. In this case, fuzzy optimization is applied to solve this CAMD problem with conflicting objectives. Each design objective is expressed in terms of a target property. First, a degree of satisfaction, $\lambda_{p}$ is introduced to each design objective, which can be expressed as a linear membership function bounded by the lower and upper bounds of its corresponding target property as shown in Equations (2) and (3). Equation (2) is applied on target properties to be minimized while Equation (3) is used on target properties to be maximized.

$\frac{V^{\mathrm{U}}-V_{p}}{V^{\mathrm{U}}-V^{\mathrm{L}}} \geq \lambda_{p}$

$\frac{V_{p}-V^{\mathrm{L}}}{V^{\mathrm{U}}-V^{\mathrm{L}}} \geq \lambda_{p}$

Note that $\mathrm{p}$ represents target property $p, V_{p}$ represents target property value, and $V^{\mathrm{L}}$ and $V^{\mathrm{U}}$ represent the lower and upper bounds of the target property respectively. Max-min aggregation method presented by Zimmermann ${ }^{20}$ is then applied to maximize all $\lambda_{p}$. This can be done by maximizing the least satisfied degree of satisfaction, so that all $\lambda_{p}$ are satisfied partially to at least the degree of $\lambda$. Hence, the overall objective now is to maximize the least satisfied objective, which is equivalent to $\lambda$.

\subsection{CASE STUDY}

\subsection{Optimization Formulation}

The objective of this case study is to identify a solvent that can replace hexane to extract carotenoids from the residual oil found in Palm Pressed Fiber (PPF). Currently, hexane is the conventionally used solvent for extraction as it offers high carotenoids extraction yield and has convenient $T_{b}$ (relatively low to limit heat consumption during solvent recovery but high enough to prevent much solvent losses during extraction). ${ }^{21}$ However, hexane is toxic to aquatic life, highly flammable and may result in fatality if swallowed or enters airways. The solubility of carotenoids in the solvent can be determined by the Hansen Solubility Parameters (HSP). The three parameters in HSP are $\delta_{d}, \delta_{p}$ and $\delta_{h}$, which represent dispersion, polar and hydrogen bonding respectively. To determine the solubility, the distance of a solvent from the centre of the Hansen solubility sphere, $R_{a}$ is calculated by Equation (4). Component A refers to the solute (carotenoids) while component B refers to the solvent. The smaller the $R_{a}$, the greater the affinity between carotenoids and solvent; thus the higher the solubility of carotenoids is in the solvent. ${ }^{22}$

$$
R_{a}^{2}=4\left(\delta_{d, A}-\delta_{d, B}\right)^{2}+\left(\delta_{p, A}-\delta_{p, B}\right)^{2}+\left(\delta_{h, A}-\delta_{h, B}\right)^{2}
$$

In this work, the four objective functions of the developed solvent are as follow: minimum boiling difference between the solvent and hexane $\left(T_{b, \text { diff }}\right)$ to ensure the solvent has a convenient $T_{b}$ like hexane, minimum heat of vaporization $\left(H_{v}\right)$ for low energy consumption during solvent recovery process, minimum $R_{a}$ for high solubility of carotenoids in the solvent, and minimum total penalty score $\left(I_{S H I}\right)$ for an inherently safer and healthier molecule.

Meanwhile, $F_{p}$, octanol-water partition coefficient $\left(\log K_{\text {ow }}\right)$, and acute toxicity (96-h $L C_{50}$ to fathead minnow) are selected as property constraints. Their respective lower bound (LB) and upper bound (UB) are shown in Table 1. GCM models developed by Hukkerikar et al., ${ }^{16}$ can be used to estimate $\delta_{d}, \delta_{p}, \delta_{h}, H_{v}$ and $\log K_{\text {ow }}$, while the GCM proposed by Martin and Young ${ }^{23}$ is utilized to calculate acute toxicity $L C_{50}$ (96-h to fathead minnow). The selected molecular blocks include $\mathrm{CH}_{3}, \mathrm{CH}_{2}, \mathrm{CH}, \mathrm{C}, \mathrm{OH}$, $\mathrm{CH}_{3} \mathrm{CO}, \mathrm{CH}_{2} \mathrm{CO}, \mathrm{CH}_{3} \mathrm{O}, \mathrm{CH}_{2} \mathrm{O}, \mathrm{CHO}, \mathrm{CH}_{3} \mathrm{COO}, \mathrm{CH}_{2} \mathrm{COO}, \mathrm{CH}_{2}$ (cyclic), $\mathrm{CH}$ (cyclic), $\mathrm{C}$ (cyclic) and $\mathrm{O}$ (cyclic), which are from the molecular fragments of the solvents used for the extraction of carotenoids.

\subsection{Fuzzy Optimization}

The four design objectives are then converted into their respective property operator, $\Omega_{p}$ as shown in Table $2 . \Omega_{p}$ is equivalent to the simple function $\mathrm{f}(\mathrm{p})$ for each target property $p$, which is exactly the left-hand side of Equation (1). The $\Omega_{p}$ range for the four properties to be optimized can be determined by optimizing each of the property one at a time to identify their respective $V^{\mathrm{L}}$ and $V^{\mathrm{U}}$, which are listed in Table 2. In order to minimize the four target properties, the linear membership function of Equation (2) is applied. The optimization model is a mixed integer nonlinear programming (MINLP) as it involves nonlinear constraints when modeling the uncertainty on the allocation of sub-index values to the molecule. Integer cuts are introduced to generate alternate solutions so that there are multiple solvents to conduct experimental verification for their performance.

Table 1: Property constraints for the developed solvent

\begin{tabular}{llc}
\hline Property & LB & UB \\
\hline$F_{p}\left({ }^{\circ} \mathrm{C}\right)$ & -1.2 & - \\
$\log K_{\text {Kow }}$ & - & 2.86 \\
$\log L C_{50}$ & 1.37 & - \\
\hline
\end{tabular}

Table 2: Target property operators for the developed solvent

\begin{tabular}{lccc}
\hline Property & $\Omega_{p}$ & $V^{\mathrm{L}}$ & $V^{\mathrm{U}}$ \\
\hline$T_{b, \text { diff }}$ & $\exp \left(T_{b} / T_{b 0}\right)$ & 0.0032 & 2.7261 \\
$H_{v}$ & $H_{v}-H_{v_{0}}$ & 14.0244 & 30.8018 \\
$R_{a}$ & $R_{a}$ & 3.5863 & 9.7779 \\
$I_{S H I}$ & $I_{S H I}$ & 8.7674 & 11.8096 \\
\hline
\end{tabular}


Table 3: The six generated solvents with their properties

\begin{tabular}{lllllllll}
\hline Solvent & $\lambda$ & $I_{S H I}$ & $R_{a}$ & $H_{v}(\mathrm{~kJ} / \mathrm{mol})$ & $T_{b}\left({ }^{\circ} \mathrm{C}\right)$ & $F_{p}\left({ }^{\circ} \mathrm{C}\right)$ & $\log K_{o w}$ & $L C_{50}(\mathrm{mg} / \mathrm{l})$ \\
\hline $\mathrm{A} 1$ & 0.404 & 10.58 & 6.634 & 35.5 & 107.2 & 16.7 & 1.56 & 68.6 \\
$\mathrm{~A} 2$ & 0.379 & 10.30 & 7.432 & 34.3 & 86.2 & 9.6 & 1.01 & 114.6 \\
$\mathrm{~A} 3$ & 0.363 & 10.34 & 7.532 & 35.2 & 101.5 & 16.0 & 1.20 & 86.3 \\
$\mathrm{~A} 4$ & 0.326 & 10.24 & 7.761 & 32.9 & 68.7 & 4.5 & 0.76 & 208.0 \\
$\mathrm{~A} 5$ & 0.215 & 11.15 & 6.271 & 30.8 & 79.7 & 2.1 & 2.06 & 224.9 \\
A6 & 0.204 & 11.19 & 6.327 & 31.7 & 95.4 & 8.5 & 2.25 & 169.3 \\
\hline
\end{tabular}

\subsection{RESULTS AND DISCUSSIONS}

The estimated properties of the six synthesized solvents are shown in Table 3, while their molecular structures are illustrated in Figure 4. Solvent A5 has the lowest $R_{a}$ and $H_{v}$, while solvent A4 has the lowest $I_{S H I}$ and $T_{b}$ but with the largest $R_{a}$. According to Yara-Varón et al., ${ }^{21}$ they found that solvent A4 (ethyl acetate) offers similar carotenoids extraction yield as compared to that of hexane. Therefore, the other five solvents with lower $R_{a}$ than solvent A4 should also exhibit compatible or better extraction yield as compared to hexane. If uncertainty were not managed on the sub-indexes, the original sub-index scores without uncertainty would be applied and solvents A1 to A4 would have a similar $I_{S H I}$ value of 10 while solvents A5 and A6 would have an ISHI score of 11. Based on their scores, the inherent hazard level of solvents A1 to A4 cannot be differentiated, while the same also applies to solvents A5 and A6. Hence, by managing uncertainty on the subindexes, it helps to calculate $I_{S H I}$ that better represents the actual inherent safety and health hazard level of the molecule.

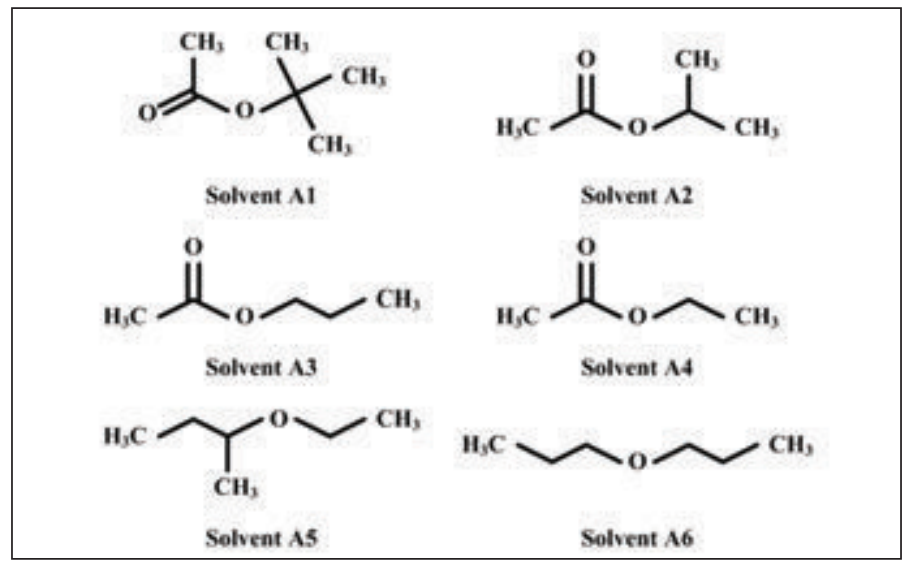

Figure 4: The generated solvents with their molecular structures

\subsection{CONCLUSIONS}

A novel CAMD method integrating the inherent safety and health sub-indexes has been developed to design molecules with reduced safety and health risks that also achieve a set of desired design properties. Several chemical-related safety and health parameters are adopted from the inherent safety and health indexes as assessment tool to measure the molecular performance. The safety and health attributes of the molecules are measured by their properties, which are estimated through property prediction methods. The uncertainties arised from these prediction models are managed on the sub-indexes to ensure that sub-index values with higher accuracy are allocated to the molecule. This ensures better representation of the safety and health performance for the molecules. A case study on the solvent design for carotenoids extraction from PPF is carried out and fuzzy optimization is applied to develop molecules that simultaneously achieve high functionality and high safety and health performance. The results show that all generated solvents demonstrate favorable performance for the extraction of carotenoids.

\section{ACKNOWLEDGEMENTS}

The financial support from the Ministry of Higher Education, Malaysia through the LRGS Grant (Project Code: LRGS/2013/ UKM-UNMC/PT/05) is gratefully acknowledged.

\section{REFERENCES}

[1] Chen, H., Pittman, W.C., Hatanaka, L.C., Harding, B.Z., Boussouf, A., Moore, D.A., Milke, J.A., Mannan, M.S., 2015. Integration of process safety engineering and fire protection engineering for better safety performance. J. Loss Prevent. Proc. $37,74-81$

[2] Khan, F., Rathnayaka, S., Ahmed, S., 2015. Methods and models in process safety and risk management: Past, present and future. Process Saf. Environ. Prot. 98, 116-147.

[3] Gebreslassie, B.G., Diwekar, U.M., 2015. Efficient ant colony optimization for computer aided molecular design: Case study solvent selection problem. Comput. Chem. Eng. 78, 1-9.

[4] Harper, P.M., Gani, R., 2000. A multi-step and multi-level approach for computer aided molecular design. Comput. Chem. Eng. 24, 677-683.

[5] Gani, R., 2004. Chemical product design: challenges and opportunities. Comput. Chem. Eng. 28, 2441-2457.

[6] Heintz, J., Belaud, J.-P., Gerbaud, V., 2014. Chemical enterprise model and decision-making framework for sustainable chemical product design. Comput. Ind. 65, 505-520.

[7] Duvedi, A.P., Achenie, L.E.K., 1996. Designing environmentally safe refrigerants using mathematical programming. Chem. Eng. Sci. 51, 3727-3739.

[8] Karunanithi, A.T., Achenie, L.E.K., Gani, R., 2006. A computeraided molecular design framework for crystallization solvent design. Chem. Eng. Sci. 61, 1247-1260.

[9] Ten, J.Y., Hassim, M.H., Ng, D.K.S., Chemmangattuvalappil, N., 2017. A molecular design methodology by the simultaneous optimization of performance, safety and health aspects. Chem. Eng. Sci. 159, 140-153. 


\section{JOON YOON TEN, ${ }^{\mathrm{a}}$ LIK YIN NG ${ }^{\mathrm{b}}$, MIMI H. HASSIM ${ }^{c}$, DENNY NG K.S. ${ }^{a}$ AND NISHANTH G. CHEMMANGATTUVALAPPIL ${ }^{\text {a* }}$}

[10] Edwards, D.W., Lawrence, D., 1993. Assessing the inherent safety of chemical process routes: Is there a relation between plant costs and inherent safety. Chem. Eng. Res. Des. 71, 252258 .

[11] Heikkilä, A.-M., 1999. Inherent safety in process plant design. An index based approach. Technical Research Centre of Finland, VTT Publications 384, Espoo.

[12] Hassim, M.H., Edwards, D.W., 2006. Development of a methodology for assessing inherent occupational health hazards. Process Saf. Environ. Prot. 84, 378-390.

[13] Hassim, M.H., Hurme, M., 2010. Inherent occupational health assessment during process research and development stage. J. Loss Prevent. Proc. 23, 127-138.

[14] Maranas, C.D., 1997. Optimal molecular design under property prediction uncertainty. AIChE J. 43, 1250-1264.

[15] Marrero, J., Gani, R., 2001. Group-contribution based estimation of pure component properties. Fluid Phase Equilib. 183-184, 183208.

[16] Hukkerikar, A.S., Sarup, B., Kate, A.T., Abildkov, J., Sin, G., Gani, R., 2012. Group-contribution+ (GC+) based estimation of properties of pure components: Improved property estimation and uncertainty analysis. Fluid Phase Equilib. 321, 25-43.

[17] Hukkerikar, A.S., Kalakul, S., Sarup, B., Young, D.M., Sin, G., Gani, R., 2012. Estimation of environment-related properties of chemicals for design of sustainable processes: Development of group-contribution+ $(\mathrm{GC}+)$ property models and uncertainty analysis. J. Chem. Inf. Model. 52, 2823-2839.

[18] Conte, E., Martinho, A., Matos, H.A., Gani, R., 2008. Combined group-contribution and atom connectivity index-based methods for estimation of surface tension and viscosity. Ind. Eng. Chem. Res. 47, 7940-7954.

[19] Frutiger, J., Marcarie, C., Abildskov, J., Sin, G., Groupcontribution based property estimation and uncertainty analysis for flammability-related properties. J. Hazard. Mater. 318, 783793.

[20] Zimmermann, H.-J., 1978. Fuzzy programming and linear programming with several objective functions. Fuzzy Set. Syst. $1,45-55$.

[21] Yara-Varón, E., Fabiano-Tixier, A.S., Balcells, M., CanelaGarayoa, R., Bily, A., Chemat, F., 2016. Is it possible to substitute hexane with green solvents for extraction of carotenoids? A theoretical versus experimental solubility study. RSC Adv. 6, 27750-27759.

[22] Hansen, C.M., 2007. Hansen solubility parameters: a user's handbook, second ed. CRC Press, Boca Raton.

[23] Martin, T.M., Young, D.M., 2001. Prediction of the acute toxicity (96-h LC50) of organic compounds to the fathead minnow (Pimephales promelas) using a group contribution method. Chem. Res. Toxicol. 14, 1378-1385.

\section{PROFILES}

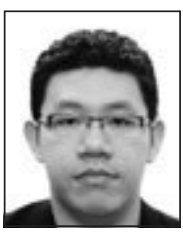

JOON YOON TEN is currently a final year Chemical Engineering PhD Student in the University of Nottingham Malaysia Campus. He received his MEng (Hons) in Chemical Engineering from the same university in 2014. His PhD research lies in the field of molecular design that incorporates the concept of inherent safety and occupational health into the computer-aided molecular design (CAMD) framework. Email: joonyoon.ten@ gmail. com

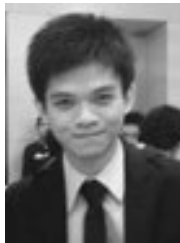

DR NG LIK YIN is an assistant professor in the Department of Chemical Engineering at University of Tunku Abdul Rahman. He received his Master of Engineering in Chemical Engineering (MEng Hons) from The University of Nottingham in year 2012. He completed his PhD in the same university in year 2015. His main areas of expertise include molecular product design and synthesis of integrated biorefinery. His current work focuses on the design of green products as well as integration and optimization of process and product design. Email: likyin.ng@gmail.com

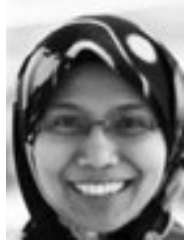

DR MIMI HASSIM is a senior lecturer of chemical engineering at the Universiti Teknologi Malaysia (UTM), Skudai. She is a Chartered Engineer with the Institution of Chemical Engineers UK (IChemE). She received her BEng degree from Universiti Teknologi Malaysia, MSc degree from Loughborough University, UK and doctoral degree from Aalto University School of Science and Technology, Finland. She is an established and world pioneer researcher working on inherent occupational health studies of chemical processes. She is the subject editor for the Process Safety and Environmental Protection, guest editor for the Process Safety and Environmental Protection (Special Issue for PSE Asia 2013) and International Journal of Process Systems Engineering as well as technical English editor for The Journal of Sustainable Development of Energy, Water and Environment Systems (JSDEWES). Email: mimi@cheme.utm.my.

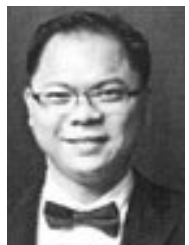

DR DENNY K. S. NG is Professor of Process Design and Integrated Biorefinery at the Department of Chemical and Environmental Engineering, The University of Nottingham, Malaysia Campus. He is currently head of Business Engagement and Innovation Services (BEIS) and Founding Director of Centre of Sustainable Palm Oil Research (CESPOR). His areas of specialization include energy management, resource conservation via process intergration techniques (pinch analysis and mathematical optimization), synthesis and analysis of biomass processing and integrated bio refineries, as well as energy planning for greenhouse gas emission reduction. Email: Denny.Ng@nottingham.edu.my.

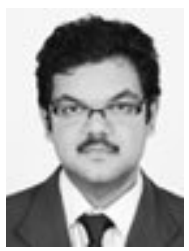

DR NISHANTH CHEMMANGATTUVALAPPIL is an Associated Professor of Chemical Engineering in the department of Chemical and Environmental Engineering at University of Nottingham Malaysia. He received his $\mathrm{PhD}$ in Chemical Engineering from Auburn University, AL, USA (2010). He worked as a Post-doctoral fellow at University of Pittsburgh, PA, USA and later at Auburn University. His main areas of expertise include product and molecular design, mixture design and integrated biorefineries. His current work focuses on the application of molecular design concepts on reactive systems, integration of molecular design techniques into the design of biorefineries and carbon capture and storage using ionic liquids. Email: Nishanth.C@nottingham.edu.my. 